\title{
Comprehensive Study of All-Solid-State Z-Scheme Photocatalytic Systems of $\mathrm{ZnO} / \mathrm{Pt} / \mathrm{CdZnS}$
}

Tayirjan Taylor Isimjan, ${ }^{* \dagger \oplus}$ Partha Maity, ${ }^{\ddagger}$ Jordi Llorca, ${ }^{\S}$ Toseef Ahmed, ${ }^{\|}$Manas R. Parida, ${ }^{\ddagger}$ Omar F. Mohammed, ${ }^{\ddagger}$ and Hicham Idriss $*,+(0)$

${ }^{\dagger}$ Fundamental Catalysis, SABIC-CRD at KAUST, Thuwal 23955-6900, Kingdom of Saudi Arabia

${ }^{\ddagger}$ KAUST Solar Center, Division of Physical Sciences and Engineering, King Abdullah University of Science and Technology (KAUST), Thuwal 23955-6900, Kingdom of Saudi Arabia

${ }^{\S}$ Institute of Energy Technologies, Department of Chemical Engineering, and Barcelona Research Center in Multiscale Science and Engineering, Technical University of Catalonia, EEBE, Barcelona 08930, Spain

"SABIC Technology Center, Riyadh 11422, Kingdom of Saudi Arabia

Supporting Information

ABSTRACT: We have investigated a Z-scheme based on a $\mathrm{ZnO} / \mathrm{Pt} / \mathrm{CdZnS}$ photocatalyst, active in the presence of a complex medium composed of acetic acid and benzyl alcohol, the effects of which on the catalyst stability and performance are studied. Transmission electron microscopy images showed uniformly dispersed sub-nanometer Pt particles. Inductively coupled plasma and X-ray photoelectron spectroscopy analyses suggested that $\mathrm{Pt}$ is sandwiched between $\mathrm{ZnO}$ and $\mathrm{CdZnS}$. An apparent quantum yield (AQY) of $34 \%$ was obtained over the $[\mathrm{ZnO}]_{4} / 1$ wt $\% \mathrm{Pt} / \mathrm{CdZnS}$ system at $360 \mathrm{~nm}, 2.5$-fold higher than that of $1 \% \mathrm{Pt} / \mathrm{CdZnS}(14 \%)$. Furthermore, an AQY of $16 \%$ was observed using $[\mathrm{ZnO}]_{4} / 1$ wt \%Pt/ $\mathrm{CdZnS}$, which was comparable to that of $1 \mathrm{wt} \% \mathrm{Pt} / \mathrm{CdZnS}(10 \%)$ at $460 \mathrm{~nm}$. On the basis of these results, we proposed a charge transfer mechanism, which was confirmed through femtosecond transient absorption spectroscopy. Finally, we identified the two main factors that affected the stability of the catalyst, which were the sacrificial reagent and the acidic $\mathrm{pH}$.

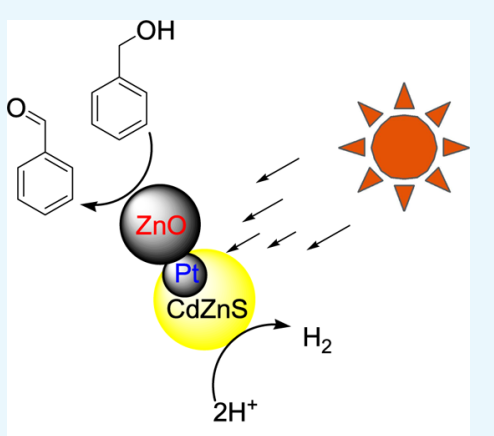

All solid-state Z-scheme

\section{INTRODUCTION}

Photocatalytic water splitting for hydrogen production employing semiconductor-based photocatalysts is considered to be the "Holy Grail" of solar energy conversion and storage. ${ }^{1}$ However, this photocatalytic process is largely limited by four factors: (1) stability with respect to photocorrosion, (2) a narrow band gap of the photocatalysts to absorb more light and suitable band edges/maximum-minimum, which match with the redox potential/level of water, (3) environmental friendliness, and (4) easy access and cost-effectiveness. These four conditions are often mutually exclusive for practical applications. Furthermore, fast charge recombination of the photocatalysts seriously reduces the solar-to-fuel conversion efficiency. ${ }^{2}$ Therefore, it is almost impossible to find a single semiconductor photocatalyst that satisfies all of these requirements. For instance, $\mathrm{ZnO}$ is the preferred material for the photoelectrode in hydrogen production. However, it has an energy band gap of about $\sim 3.2 \mathrm{eV}$; therefore, it mostly absorbs the ultraviolet portion of the solar spectrum, which is less than $5 \%$ of total solar energy. As an alternative, cadmium sulfide-based narrow band gap semiconductors, such as $\mathrm{Cd}_{x} \mathrm{Zn}_{1-x} \mathrm{~S}$, also have been extensively investigated due to their band gap tunability, and better charge mobility compare to those of $\mathrm{CdS}{ }^{3}$ The photocatalytic activity of various morphologies of $\mathrm{Cd}_{x} \mathrm{Zn}_{1-x} \mathrm{~S}$, including nanoparticles, ${ }^{4}$ nanotwins, ${ }^{5}$ nanoflowers, ${ }^{6}$ and volvox- like structures, ${ }^{7}$ was investigated. Despite the suitable band gap and high quantum efficiency, these types of CdS-based photocatalysts suffer from catalytic decay even with sacrificial reagents because the sulfide is easily oxidized to elemental sulfur by photogenerated holes. Therefore, effective removal of holes from CdS-based light absorbers is the key for long-term stability of this type of photocatalysts. Nevertheless, these limitations of CdS-based single semiconductors can be mitigated by designing a heterogeneous $\mathrm{p}-\mathrm{n}$ junction system. A $p-n$ junction is a boundary or interface between $p$-type and n-type semiconductors, which improves charge separation through band bending. However, in this process, the redox potentials of electrons and holes are reduced; ${ }^{8}$ as a result, it is impossible to obtain a system that has higher charge separation as well as higher or suitable redox potentials simultaneously. Therefore, it is necessary to explore new types of multijunction photocatalysts that can overcome the drawbacks of a $p-n$ junction system. The actual solution for this problem can be found in nature; for instance, plants use a $\mathrm{Z}$-scheme photocatalytic process to convert $\mathrm{H}_{2} \mathrm{O}$ and $\mathrm{CO}_{2}$ into carbohydrate and $\mathrm{O}_{2}$, which is a two-step photoexcitation

Received: June 11, 2017

Accepted: August 7, 2017

Published: August 22, 2017 
process. $^{1,9}$ In step 1, the highest occupied molecular orbital (HOMO) electrons of an oxygen-evolving complex (photosystem II, PS II) are excited to the lowest unoccupied molecular orbital (LUMO) of PS II under solar light and then the electrons in LUMO of PS II are transferred to the HOMO of ferredoxin-NAPD reductase (PS I), through the electron mediator. In step 2, the HOMO (photosystem I, PS I) electrons of PS I are excited to its LUMO (PS I). As a result, the photogenerated electrons and holes are left in the LUMO (PS I) and the HOMO (PS II), respectively. Finally, the photogenerated electrons in the LUMO (PS I) are used to reduce $\mathrm{CO}_{2}$, whereas the photogenerated holes in the HOMO of PS II are used to oxidize $\mathrm{H}_{2} \mathrm{O}$. In light of that, artificial Zscheme-based photocatalytic systems have been widely investigated. ${ }^{10}$ The nature-mimicked Z-scheme photocatalytic system not only shows high redox potentials but also has a slow charge recombination rate in addition to enhanced light absorption. ${ }^{9 \mathrm{~b}}$ Despite their limitations as mentioned above as single semiconductors, $\mathrm{ZnO}$ and $\mathrm{Cd}_{x} \mathrm{Zn}_{1-x} \mathrm{~S}$ together can form an efficient Z-scheme system due to their compatible lattice structures and suitable band gap alignment, which lead to excellent charge migration through the interface and consequently facilitate the effective interband charge transfer from $\mathrm{Cd}_{x} \mathrm{Zn}_{1-x} \mathrm{~S}$ to $\mathrm{ZnO}^{11}$ Recently, Rao et al. have reported $[\mathrm{ZnO}]_{4} / 1 \% \mathrm{Pt} / \mathrm{Cd}_{0.8} \mathrm{Zn}_{0.2} \mathrm{~S}$ heterojunction structures that show a high quantum yield under visible light. ${ }^{12}$ However, to the best of our knowledge, there are no systematic studies on this particular photocatalyst in terms of the charge transfer mechanism and stability due to the complexity of the system. Therefore, we used $\mathrm{ZnO} / \mathrm{Pt} / \mathrm{CdZnS}$ as a model system to perform a detailed analysis on the Z-scheme.

In this work, we first synthesized and characterized $\mathrm{ZnO} / \mathrm{Pt} /$ $\mathrm{Cd}_{0.8} \mathrm{Zn}_{0.2} \mathrm{~S}$ and its two main components, $\mathrm{Pt} / \mathrm{ZnO}$ and $\mathrm{Pt} /$ $\mathrm{Cd}_{0.8} \mathrm{Zn}_{0.2} \mathrm{~S}$, and performed detailed analysis of their contributions to the photocatalytic activity of $\mathrm{ZnO} / \mathrm{Pt} / \mathrm{Cd}_{0.8} \mathrm{Zn}_{0.2} \mathrm{~S}$. Then, we studied the effect of $\mathrm{Pt}$ content on the overall photoactivities of $\mathrm{ZnO} / \mathrm{Pt} / \mathrm{Cd}_{0.8} \mathrm{Zn}_{0.2} \mathrm{~S}$ and evaluated the factors that affect the stability of this type of photocatalysts. In addition, we also investigated charge carrier dynamics using femtosecond transient absorption (TA) spectroscopy. Finally, we proposed the possible charge transfer mechanism and verified experimentally the proposed Z-scheme.

\section{RESULTS AND DISCUSSION}

2.1. Characterization. The X-ray diffraction (XRD) patterns of various catalysts are depicted in Figure 1. The $\mathrm{ZnO} / \mathrm{Pt} / \mathrm{CdZnS}$ hybrid system shows a clear mixture of hexagonal $\mathrm{ZnO}$ and cubic $\mathrm{Cd}_{0.8} \mathrm{Zn}_{0.2} \mathrm{~S}$ phases. The three diffraction peaks of all of the $\mathrm{Cd}_{0.8} \mathrm{Zn}_{0.2} \mathrm{~S}$-based materials with $2 \theta$; values of $26.9,44.6$, and $52.8^{\circ}$ represent the (111), (220), and $(311)^{13}$ planes of the zinc-blend phase, respectively. All peaks are broad due to the high content of $\mathrm{Cd}$ in the solid solution, which causes a significant increase of unit cell parameters because of large differences of their ion radius $\left(\mathrm{Cd}^{2+}(0.78 \AA) \text { and } \mathrm{Zn}^{2+}(0.68 \AA)\right)^{14}$ and small particle sizes $(<10 \mathrm{~nm})$ of each component, as shown by transmission electron microscopy (TEM) images (Figure 3). Because the solid solution of $\mathrm{Cd}_{0.8} \mathrm{Zn}_{0.2} \mathrm{~S}$ was synthesized at low temperature $\left(60{ }^{\circ} \mathrm{C}\right)$, the main crystal composition is a zinc-blend cubic phase (Figure 1). Similar results were reported by Chen et al., ${ }^{14}$ where a minor wurtzite phase starts to appear once the $\mathrm{Cd}$ content is higher than $48 \%$ in $\mathrm{Cd}_{x} \mathrm{Zn}_{1-x} \mathrm{~S}$ solid solution when the system was synthesized at low temperature. The two

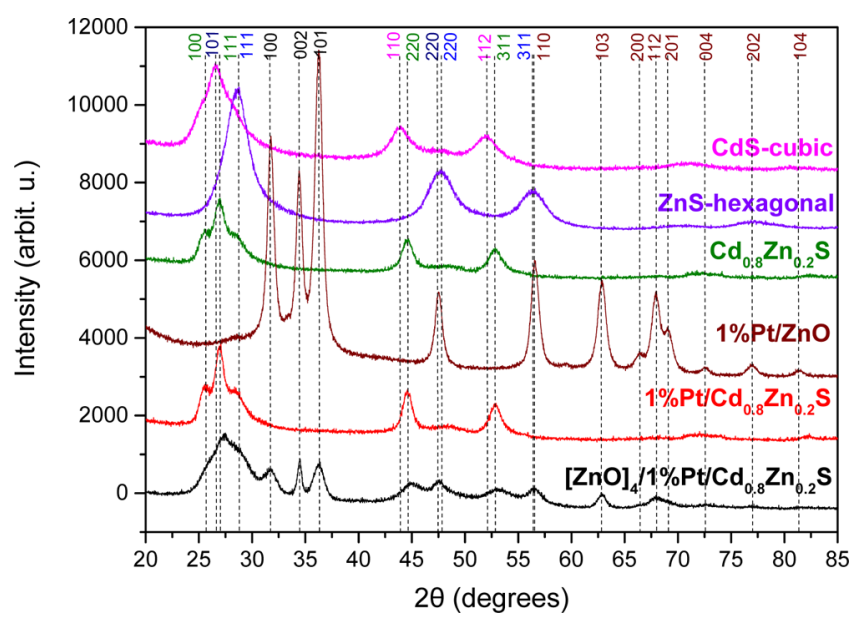

Figure 1. XRD patterns of $\mathrm{Cd}_{0.8} \mathrm{Zn}_{0.2} \mathrm{~S}$-based systems: $\mathrm{CdS}$, cubic (pink); $\mathrm{ZnS}$, hexagonal (purple); $\mathrm{Cd}_{0.8} \mathrm{Zn}_{0.2} \mathrm{~S}$ (green); $1 \% \mathrm{Pt} / \mathrm{ZnO}$ (brown); $1 \% \mathrm{Pt} / \mathrm{Cd}_{0.8} \mathrm{Zn}_{0.2} \mathrm{~S}$ (red); $[\mathrm{ZnO}]_{4} / 1 \% \mathrm{Pt} / \mathrm{Cd}_{0.8} \mathrm{Zn}_{0.2} \mathrm{~S}$ (black).

small shoulder peaks at 25.3 and $28.5^{\circ}$ in Figure 1, corresponding to the (100) and (101) crystal planes of wurtzite, indicate a mixed phase in the solid solutions $\left(\mathrm{Cd}_{0.8} \mathrm{Zn}_{0.2} \mathrm{~S}\right.$ and $\left.1 \% \mathrm{Pt} / \mathrm{Cd}_{0.8} \mathrm{Zn}_{0.2} \mathrm{~S}\right)$, but it is not obvious in the case of the hybrid system $\left([\mathrm{ZnO}]_{4} / 1 \% \mathrm{Pt} / \mathrm{Cd}_{0.8} \mathrm{Zn}_{0.2} \mathrm{~S}\right)$. However, high-resolution TEM images of $[\mathrm{ZnO}]_{4} / 0.1 \% \mathrm{Pt} /$ $\mathrm{Cd}_{0.8} \mathrm{Zn}_{0.2} \mathrm{~S}$ (Figure 3) show some wurtzite hexagonal phases of $\mathrm{Cd}_{0.8} \mathrm{Zn}_{0.2} \mathrm{~S}$. Therefore, one can conclude that both the solid solution and the hybrid system are formed by mixed phases but the dominant phase is the zinc-blended phase. Because lattice parameters of cubic $\mathrm{Cd}_{x} \mathrm{Zn}_{1-x} \mathrm{~S}$ solid solutions follow Vergard's law, ${ }^{15}$ which describes a linear relationship between $x$ and lattice parameters, the $\mathrm{Cd}$ contents $(x)$ were calculated according to eq 1 .

$$
a\left(\mathrm{Cd}_{x} \mathrm{Zn}_{1-x} \mathrm{~S}\right)=a(\mathrm{CdS}) \times x+a(\mathrm{ZnS}) \times(1-x)
$$

Here, $a\left(\mathrm{Cd}_{x} \mathrm{Zn}_{1-x} \mathrm{~S}\right)$ is the lattice parameter of the $\mathrm{Cd}_{x} \mathrm{Zn}_{1-x} \mathrm{~S}$ solid solution, $a(\mathrm{CdS})$ and $a(\mathrm{ZnS})$ are the lattice parameters of $\mathrm{CdS}$ and $\mathrm{ZnS}$, respectively, and $x$ is the molar fraction of $\mathrm{Cd}$ in the solution. The $\mathrm{Cd}$ contents in the solid solutions were calculated to be $0.78 \pm 0.02$. Because the error is less than $3 \%$, the $\mathrm{Cd}$ content is assumed to be the same in all of the cases as 0.8. All of the characteristic peaks of $\mathrm{Cd}_{0.8} \mathrm{Zn}_{0.2} \mathrm{~S}$, whether alone or with $\mathrm{ZnO}$, show a clear shift toward a higher angle, indicating the formation of a solid solution. The crystal sizes of $\mathrm{ZnO}$ plus $\mathrm{Cd}_{0.8} \mathrm{Zn}_{0.2} \mathrm{~S}$ both in separate and mixed phases in the $\mathrm{Z}$-scheme are calculated according to Scherrer's equation. The results show that the crystal sizes of $\mathrm{ZnO}$ and $\mathrm{Cd}_{0.8} \mathrm{Zn}_{0.2} \mathrm{~S}$ are the same in both conditions, which are around 10 and $6 \mathrm{~nm}$, respectively.

The optical band gaps of the $\mathrm{Cd}_{0.8} \mathrm{Zn}_{0.2} \mathrm{~S}$-based systems were determined by the Tauc plot; ${ }^{16}$ the optical band gap $\left(E_{\mathrm{g}}\right)$ can be obtained in the wavelength range $450-750 \mathrm{~nm}$ from the straight line plot between $(\alpha h v)^{1 / 2}(\alpha$ is the absorption coefficient) and photon energy $(h v)$. There are slight differences in the $E_{g}$, as shown in Figure 2, which could be associated with slight differences of $\mathrm{Cd}$ concentration in the solid solution during sample preparation. The $E_{\mathrm{g}}$ of the $\mathrm{Cd}_{0.8} \mathrm{Zn}_{0.2} \mathrm{~S}$-based hybrid systems were found to be between 2.2 and $2.3 \mathrm{eV}$ (Figure 2, inset).

Figure 3 shows the TEM images of an overall view of asprepared $[\mathrm{ZnO}]_{4} / \mathrm{Pt} / \mathrm{Cd}_{0.8} \mathrm{Zn}_{0.2} \mathrm{~S}$, which is constituted by small 


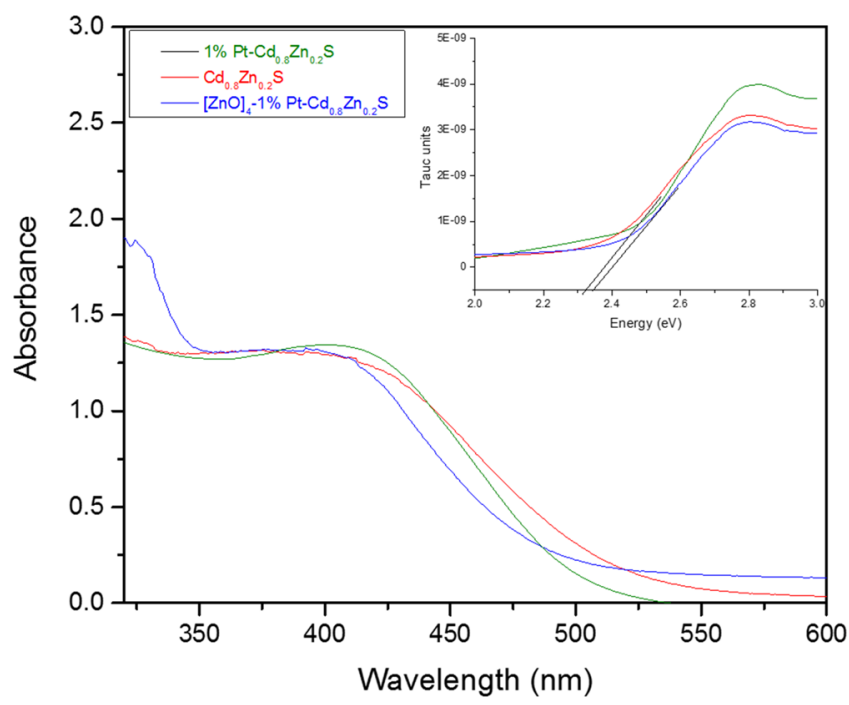

Figure 2. UV-vis absorption spectra of $\mathrm{Cd}_{0.8} \mathrm{Zn}_{0.2} \mathrm{~S}$-based materials. Inset: Tauc plots of $\mathrm{Cd}_{0.8} \mathrm{Zn}_{0.2} \mathrm{~S}$-based materials. particles, quite homogeneous in size. An enlargement of the area inside the square in Figure 3a shows a very homogeneous distribution of particles with an average particle size of $5 \mathrm{~nm}$ $\left(\mathrm{Cd}_{0.8} \mathrm{Zn}_{0.2} \mathrm{~S}\right)$, which is slightly smaller than that estimated by $\mathrm{XRD}$ (Figure 1). It is interesting to note, however, that particles with different crystallinities are seen, ranging from almost amorphous to very well faceted ones. This is particularly visible in the insets of the Fourier transform (FT) image of the particle in Figure $3 \mathrm{~b}$. The spots at 3.36 and $3.16 \AA$ correspond well to the (002) and (101) crystallographic planes of hexagonal $\mathrm{Cd}_{0.8} \mathrm{Zn}_{0.2} \mathrm{~S}$, whereas the spots at 2.72 and $3.14 \AA$ represent the (200) and (111) planes of the cubic crystal phase, respectively. Furthermore, the (101) plane of hexagonal $\mathrm{ZnO}$ is also observed. In Figure $3 c$, the several small particles with high electron contrast (marked by white arrows) can be ascribed to a Pt-containing phase. They are subnanometric and very well dispersed. HAADF-STEM was performed to study the microstructure of the catalyst. The EDX analysis shows strong signals of $\mathrm{Zn}, \mathrm{Cd}$, and $\mathrm{S}$; they are likely the mixed phases of $\mathrm{ZnO}$ and $\mathrm{Cd}_{0.8} \mathrm{Zn}_{02} \mathrm{~S}$. Both phases are extremely well mixed. Figure $1 \mathrm{~S}$ shows the X-ray photoelectron spectroscopy (XPS) survey spectra of $0.1 \% \mathrm{Pt} / \mathrm{Cd}_{0.8} \mathrm{Zn}_{0.2} \mathrm{~S}, 1 \% \mathrm{Pt} / \mathrm{Cd}_{0.8} \mathrm{Zn}_{0.2} \mathrm{~S}$,
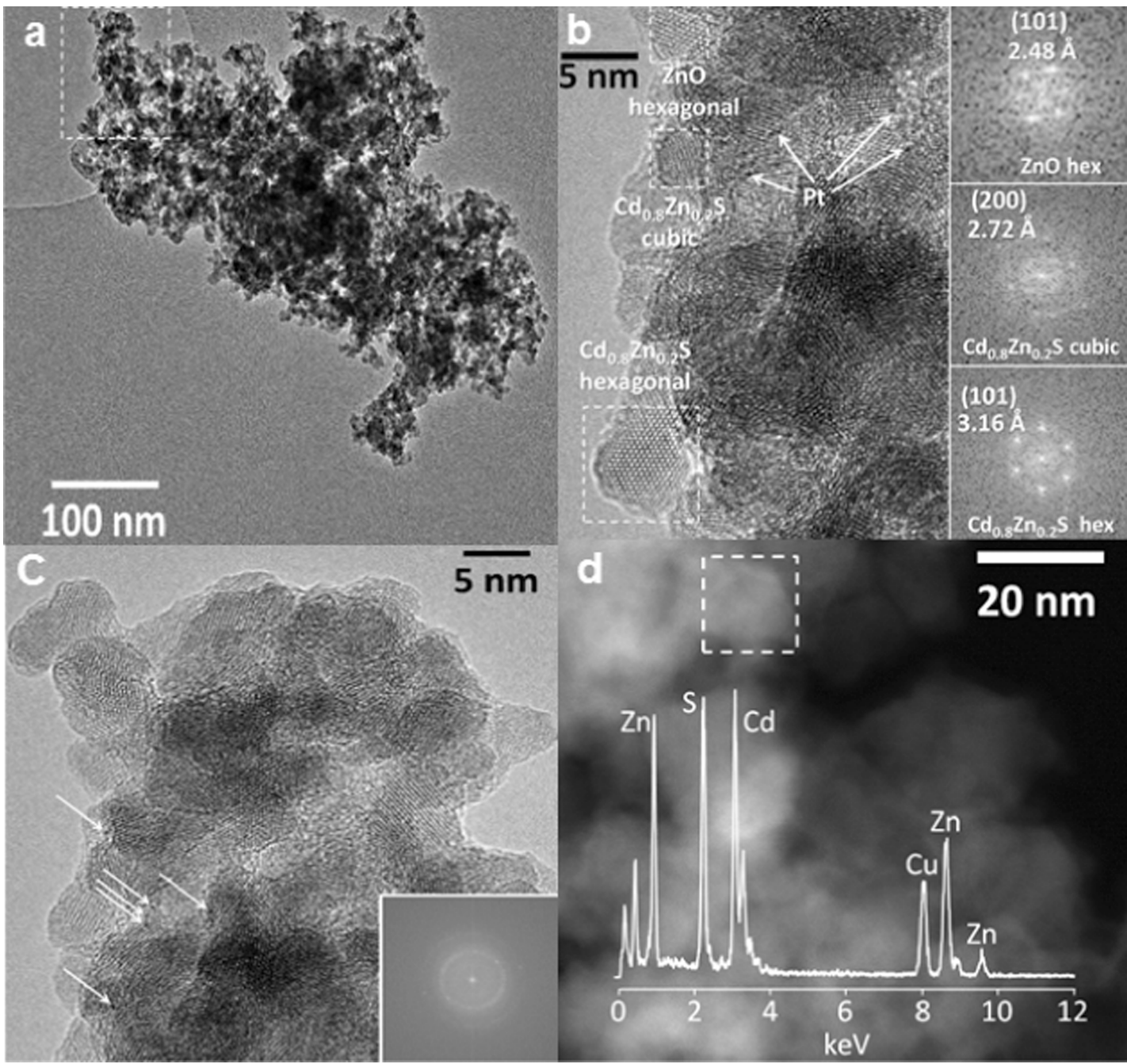

Figure 3. TEM images of $[\mathrm{ZnO}]_{4} / 0.1 \% \mathrm{Pt} / \mathrm{Cd}_{0.8} \mathrm{Zn}_{0.2} \mathrm{~S}$ : (a) low-magnification image; (b) high-magnification image with Fourier transform (FT) analysis; (c) high-magnification image with the selected-area electron diffraction pattern, the arrows indicate Pt entities; and (d) high-angle annular dark-field scanning transmission electron microscopy (HAADF-STEM) image with energy dispersive X-ray (EDX) analysis corresponding to the area inside the white square. 
Table 1. Binding Energies (eV) of Core Electrons of the $\mathrm{Cd}_{0.8} \mathrm{Zn}_{0.2} \mathrm{~S}$-Based Photocatalysts Obtained from XPS Experiments

\begin{tabular}{|c|c|c|c|c|c|c|c|}
\hline samples & $\mathrm{Cd} 3 \mathrm{~d}_{5 / 2}$ & $\mathrm{Zn} 2 \mathrm{p}_{3 / 2}$ & $\mathrm{~S} 2 \mathrm{p}_{3 / 2}$ & Pt $4 f_{7 / 2}$ & $\mathrm{O}$ 1s $(\mathrm{ZnO})$ & $\mathrm{O}$ 1s $(\mathrm{OH})$ & $\mathrm{O}$ 1s $\left(\mathrm{H}_{2} \mathrm{O}\right)$ \\
\hline $0.1 \% \mathrm{Pt} / \mathrm{Cd}_{0.8} \mathrm{Zn}_{0.2} \mathrm{~S}$ & 404.8 & 1022.1 & 161.1 & 72.0 & & 531.3 & 532.9 \\
\hline $1 \% \mathrm{Pt} / \mathrm{Cd}_{0.8} \mathrm{Zn}_{0.2} \mathrm{~S}$ & 404.8 & 1022.1 & 161.1 & 71.9 & & 531.6 & 533.0 \\
\hline$[\mathrm{ZnO}]_{4} / 0.1 \% \mathrm{Pt} / \mathrm{Cd}_{0.8} \mathrm{Zn}_{0.2} \mathrm{~S}$ & 404.7 & 1022.0 & 161.0 & & 530.0 & 531.5 & \\
\hline$[\mathrm{ZnO}]_{4} / 1 \% \mathrm{Pt} / \mathrm{Cd}_{0.8} \mathrm{Zn}_{0.2} \mathrm{~S}$ & 404.8 & 1022.4 & 161.2 & & 530.3 & 531.7 & \\
\hline reference & 9 & 18,19 & 21 & 22 & 20 & & \\
\hline
\end{tabular}
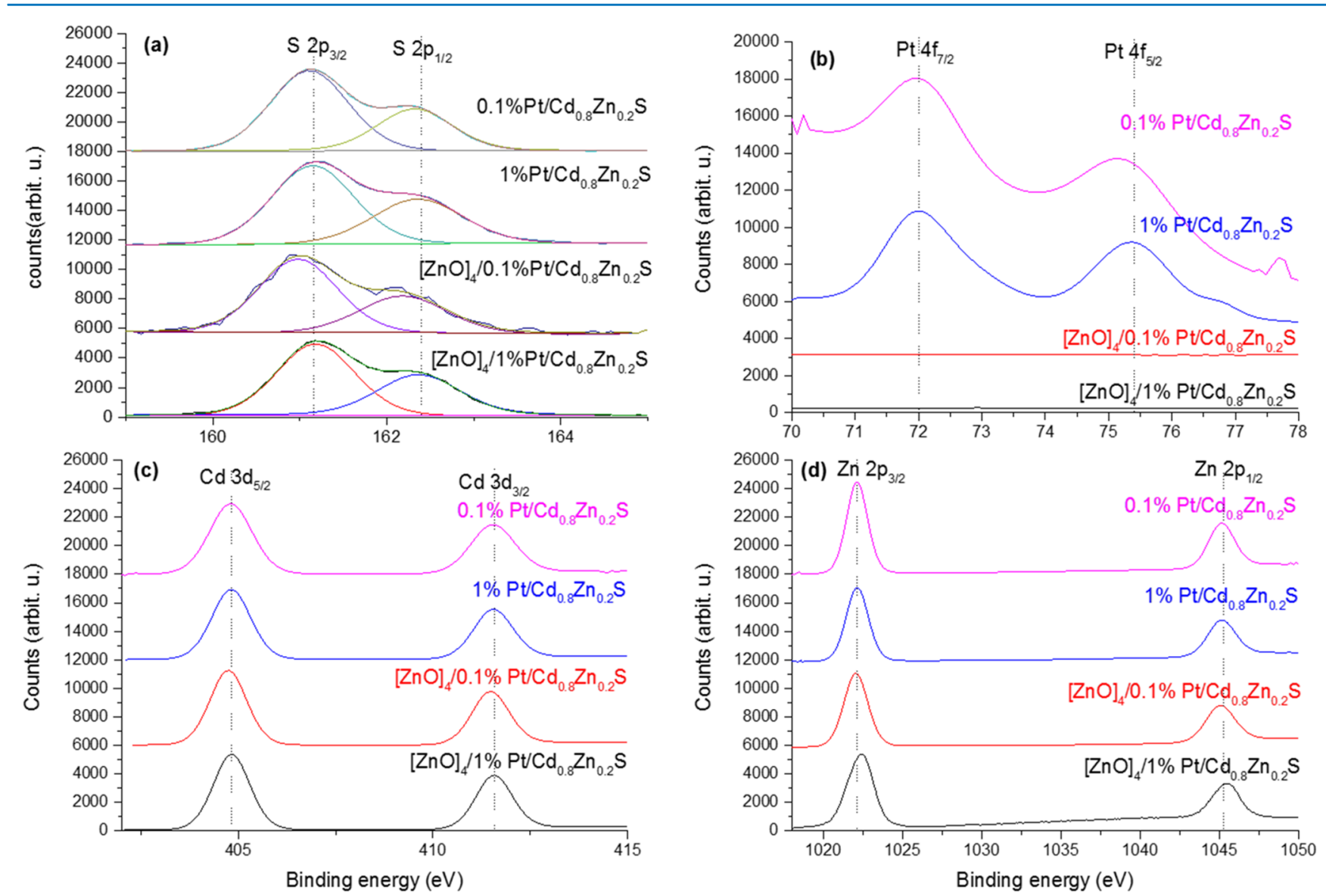

Figure 4. XPS spectra of the $\mathrm{ZnO} / \mathrm{Pt} / \mathrm{Cd}_{0.8} \mathrm{Zn}_{0.2} \mathrm{~S}$ system: (a) S 2p, (b) Pt 4f, (c) Cd 3d, and (d) $\mathrm{Zn} 2 \mathrm{p}$.

$[\mathrm{ZnO}]_{4} / 0.1 \% \mathrm{Pt} / \mathrm{Cd}_{0.8} \mathrm{Zn}_{0.2} \mathrm{~S}$, and $[\mathrm{ZnO}]_{4} / 1 \% \mathrm{Pt} / \mathrm{Cd}_{0.8} \mathrm{Zn}_{0.2} \mathrm{~S}$, which confirm the coexistence of $\mathrm{Cd}, \mathrm{Zn}, \mathrm{S}$, and Pt. The binding energies of $\mathrm{Cd} 3 \mathrm{~d}_{5 / 2}, \mathrm{Zn} 2 \mathrm{p}_{3 / 2}, \mathrm{~S} 2 \mathrm{p}_{3 / 2}$, and $\mathrm{O} 1 \mathrm{~s}$ are recorded in Table 1 with the corresponding references.

The range of binding energies of $\mathrm{Zn} 2 \mathrm{p}_{3 / 2}$ of all of the samples are between $1022.2 \pm 0.2 \mathrm{eV}$ and they are close to each other which are similar to that reported for $\mathrm{ZnO}^{17}$ and $\mathrm{ZnS}^{18}$ (Figure 4d). Therefore, establishing an accurate assignment for both $\underline{\mathrm{Zn}}^{\underline{2+}}(\mathrm{ZnO})$ and $\underline{\mathrm{Zn}}^{\underline{2+}}(\mathrm{ZnS})$ is difficult. However, the presence of metal oxide can be verified by analyzing the chemical states of oxygen in the system. For example, the $\mathrm{O} 1 \mathrm{~s}$ peaks from $\mathrm{Pt} / \mathrm{Cd}_{0.8} \mathrm{Zn}_{0.2} \mathrm{~S}$ and $\mathrm{ZnO} / \mathrm{Pt} / \mathrm{Cd}_{0.8} \mathrm{Zn}_{0.2} \mathrm{~S}$ show three oxygen species in different chemical environments, where the peaks at $\sim 530.0,531.5$, and $533.0 \mathrm{eV}$ are ascribed to $\mathrm{Zn}-\underline{\mathrm{O}}$, $\mathrm{CH}_{3} \underline{\mathrm{O}}-\mathrm{H}(-\underline{\mathrm{OH}})$ (from solvent), and $\mathrm{H}-\underline{\mathrm{O}}-\mathrm{H}$, respectively ${ }^{19}$ (Figure S2). Interestingly, the surface-adsorbed water is only detected on the surface of a nonhybrid system such as $0.1 \% \mathrm{Pt}$ / $\mathrm{Cd}_{0.8} \mathrm{Zn}_{0.2} \mathrm{~S}$ and $1 \% \mathrm{Pt} / \mathrm{Cd}_{0.8} \mathrm{Zn}_{0.2} \mathrm{~S}$. Furthermore, the signal intensity of $\mathrm{Zn}-\mathrm{O}$ became much weaker in the case of $\mathrm{ZnO} /$ $1 \% \mathrm{Pt} / \mathrm{Cd}_{0.8} \mathrm{Zn}_{0.2} \mathrm{~S}$ compared to that of $\mathrm{ZnO} / 0.1 \% \mathrm{Pt} /$ $\mathrm{Cd}_{0.8} \mathrm{Zn}_{0.2} \mathrm{~S}$, which can be interpreted in terms of encapsulation of $\mathrm{ZnO}$ by $\mathrm{Cd}_{0.8} \mathrm{Zn}_{0.2} \mathrm{~S}$ in the hybrid systems. The $\mathrm{S} 2 \mathrm{p}_{3 / 2}$ peaks of the samples are close to $161.0 \mathrm{eV}$, characteristic of the presence of $\mathrm{S}^{2-}$ species on the surface ${ }^{20}$ (Figure $4 \mathrm{a}$ ). Furthermore, no other sulfur species are detected, which indicates that $\mathrm{S}^{2-}$ species were not oxidized during the synthesis.

The peaks at around $404.7 \mathrm{eV}$ in Figure 4c correspond to $\mathrm{Cd}$ $3 \mathrm{~d}_{5 / 2}$ and are ascribed to $\mathrm{Cd}-\mathrm{S}$ bonds. ${ }^{7}$ The binding energies of Pt $4 f_{7 / 2}$ of the samples are almost identical (Figure $4 \mathrm{~b}$ ). In general, the $\mathrm{Pt} 4 \mathrm{f}_{7 / 2}$ binding energy of bulk metal platinum is around $71.1 \mathrm{eV}$, whereas the binding energy of $\mathrm{Pt} 4 \mathrm{f}_{7 / 2}$ increases with decreasing the particle size of $\mathrm{Pt}^{21,22}$ Then, the binding energy of $\mathrm{Pt} 4 \mathrm{f}_{7 / 2}$ recorded at $72.0 \mathrm{eV}$ indicates the presence of very small $\mathrm{Pt}$ particles on the surface, in accordance with high-resolution TEM (Figure 3). Inductively coupled plasma (ICP) and XPS analyses suggest that Pt may be sandwiched between $\mathrm{ZnO}$ and $\mathrm{Cd}(\mathrm{Zn}) \mathrm{S}$. This is because $1 \mathrm{wt}$ $\% \mathrm{Pt}$, detected by ICP and TEM, is not detectable by XPS in the same hybrid system, even though XPS could detect concentrations down to $0.1 \mathrm{wt} \% \mathrm{Pt}$ in the absence of $\mathrm{ZnO}$ (the nonhybrid system, Figure 4b). 
2.2. Photocatalytic Tests. Photocatalytic hydrogen generation was evaluated at $42.5 \mathrm{~mW} / \mathrm{cm}^{2}$ using an aqueous solution of benzyl alcohol and acetic acid $(2.5-2.5 \% \mathrm{v} / \mathrm{v})$ as a sacrificial reagent, which was reported to yield high quantum yields. $^{12}$ The $\mathrm{pH}$ of the solution was 2.5 . Figure 5 shows a

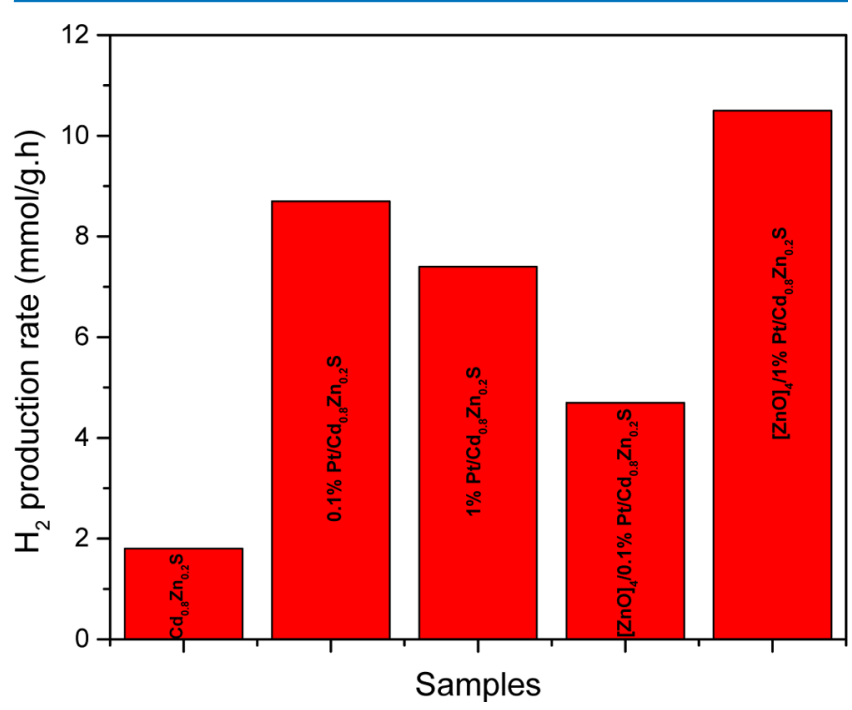

Figure 5. Rate of photocatalytic hydrogen generation of $\mathrm{Cd}_{0.8} \mathrm{Zn}_{0.2} \mathrm{~S}$ based photocatalysts in an aqueous solution of benzyl alcohol and acetic acid $(2.5-2.5 \% \mathrm{v} / \mathrm{v})$ under $42.5 \mathrm{~mW} / \mathrm{cm}^{2}$ irradiation of a xenon lamp.

comparison of the photocatalytic hydrogen generation activity of the as-prepared samples. The highest hydrogen production rate was achieved for $[\mathrm{ZnO}]_{4} / 1 \% \mathrm{Pt} / \mathrm{Cd}_{0.8} \quad \mathrm{Zn}_{0.2} \mathrm{~S}$, which is likely due to the effect of the $\mathrm{Z}$-scheme between $\mathrm{ZnO}$ and $\mathrm{Cd}_{0.8} \mathrm{Zn}_{0.2} \mathrm{~S}$ through Pt. No $\mathrm{H}_{2}$ was detected when $\mathrm{Pt} / \mathrm{ZnO}$ alone was used even after $5 \mathrm{~h}$ of irradiation, suggesting that $\mathrm{ZnO}$ was not stable at $\mathrm{pH}=2.5$. However, $\mathrm{ZnO} / \mathrm{Pt} / \mathrm{Cd}_{0.8} \mathrm{Zn}_{0.2} \mathrm{~S}$ showed good stability and better activity under such a condition due to the encapsulation of $\mathrm{ZnO}$ by $\mathrm{Cd}_{0.8} \mathrm{Zn}_{0.2} \mathrm{~S}$. To study the effect of each component of $\mathrm{ZnO} / \mathrm{Pt} / \mathrm{Cd}_{0.8} \mathrm{Zn}_{0.2} \mathrm{~S}$ on the $\mathrm{Z}$ scheme, different combinations of $\mathrm{ZnO}, \mathrm{Pt}$, and $\mathrm{Cd}_{0.8} \mathrm{Zn}_{0.2} \mathrm{~S}$ were prepared $\left(\mathrm{Pt} / \mathrm{ZnO}\right.$ and $\left.\mathrm{Pt} / \mathrm{Cd}_{0.8} \mathrm{Zn}_{0.2} \mathrm{~S}\right)$. The hydrogen generation activities in the broad light spectrum $(360-700 \mathrm{~nm}$ ) and the corresponding quantum yields at 365 and $460 \mathrm{~nm}$ were compared to those of $\mathrm{ZnO} / \mathrm{Pt} / \mathrm{Cd}_{0.8} \mathrm{Zn}_{0.2} \mathrm{~S}$. Both $\mathrm{ZnO} / \mathrm{Pt}$ / $\mathrm{Cd}_{0.8} \mathrm{Zn}_{0.2} \mathrm{~S}$ and $\mathrm{Pt} / \mathrm{Cd}_{0.8} \mathrm{Zn}_{0.2} \mathrm{~S}$ showed much higher hydrogen generation rates than those of $\mathrm{Cd}_{0.8} \mathrm{Zn}_{0.2} \mathrm{~S}$ regardless of the quantity of Pt. This could arise from the increase in the chargeseparation efficiency because of the electron transfer from the semiconductor to $\mathrm{Pt}$. In addition, the photocatalytic activity of $[\mathrm{ZnO}]_{4} / 1 \% \mathrm{Pt} / \mathrm{Cd}_{0.8} \mathrm{Zn}_{0.2} \mathrm{~S}$ was around $50 \%$ higher than that of $1 \% \mathrm{Pt} / \mathrm{Cd}_{0.8} \mathrm{Zn}_{0.2} \mathrm{~S}$, which highlights the positive contribution of $\mathrm{ZnO}$ to the photoactivity. To quantify the actual contribution of $\mathrm{ZnO}$, the apparent quantum yields (AQYs) of both photocatalysts were measured using the same quantities present in the hybrid system (Table 2). For instance, the maximum hydrogen generation rate of $[\mathrm{ZnO}]_{4} / 1 \% \mathrm{Pt} / \mathrm{Cd}_{0.8} \mathrm{Zn}_{0.2} \mathrm{~S}$ was obtained with $33 \mathrm{mg}$ of catalyst in $30 \mathrm{~mL}$ of sacrificial reagent (33 mg cat/30 mL sac.), which contain $10 \mathrm{mg}$ of $\mathrm{Cd}_{0.8} \mathrm{Zn}_{0.2} \mathrm{~S}$ and $23 \mathrm{mg}$ of $\mathrm{ZnO}$, respectively. The result reveals that when the catalysts were illuminated at $365 \mathrm{~nm}$, where both $\mathrm{ZnO}$ and $\mathrm{Cd}_{0.8} \mathrm{Zn}_{0.2} \mathrm{~S}$ were activated at the same time, the AQY of $[\mathrm{ZnO}]_{4} / 1 \% \mathrm{Pt} / \mathrm{Cd}_{0.8} \mathrm{Zn}_{0.2} \mathrm{~S}(33 \mathrm{mg} / 30 \mathrm{~mL})$ was over 2 times higher than that of $1 \% \mathrm{Pt} / \mathrm{Cd}_{0.8} \mathrm{Zn}_{0.2} \mathrm{~S}(10 \mathrm{mg} / 30 \mathrm{~mL})$, whereas $1 \% \mathrm{Pt} / \mathrm{ZnO}$ was not producing any hydrogen. Therefore, it can be concluded that the $[\mathrm{ZnO}]_{4} / 1 \% \mathrm{Pt} / \mathrm{Cd}_{0.8} \mathrm{Zn}_{0.2} \mathrm{~S}$ hybrid system follows a Z-scheme mechanism at $365 \mathrm{~nm}$, as shown in Figure 6a. In this case, the $\mathrm{Z}$-scheme simultaneously generates valence band (VB)-holes on $\mathrm{ZnO}$ with a higher oxidation potential and conduction band (CB)-electrons on $\mathrm{Cd}_{0.8} \mathrm{Zn}_{0.2} \mathrm{~S}$ with a higher reduction potential compared to those of $\mathrm{ZnO}$ and $\mathrm{Cd}_{0.8} \mathrm{Zn}_{0.2} S$. Consequently, the maximum redox potentials of the hybrid system were utilized, thus resulting in higher photocatalytic activities. Interestingly, a significantly higher $\mathrm{AQY}$ was also obtained by $\mathrm{ZnO}_{4} / 1 \% \mathrm{Pt} / \mathrm{Cd}_{0.8} \mathrm{Zn}_{0.2} \mathrm{~S}$ compared to that of $1 \%$ $\mathrm{Pt} / \mathrm{Cd}_{0.8} \mathrm{Zn}_{0.2} \mathrm{~S}$ when both catalysts were illuminated at $460 \mathrm{~nm}$ (Table 2). Although only the $\mathrm{Cd}_{0.8} \mathrm{Zn}_{0.2} \mathrm{~S}$ portion of $[\mathrm{ZnO}]_{4} /$ $1 \% \mathrm{Pt} / \mathrm{Cd}_{0.8} \mathrm{Zn}_{0.2} \mathrm{~S}$ was exited at $460 \mathrm{~nm}$, a higher AQY was achieved likely because the photogenerated electrons from $\mathrm{CB}$ of $\mathrm{Cd}_{0.8} \mathrm{Zn}_{0.2} \mathrm{~S}$ were relocated to the $\mathrm{CB}$ of $\mathrm{ZnO}$ and then transferred to $\mathrm{Pt}$, resulting in a better charge separation, which in turn leads to a higher activity. A similar phenomenon was reported on various hybrid materials. ${ }^{23}$ In contrast, deactivations were observed at both 365 and $460 \mathrm{~nm}$ when the $[\mathrm{ZnO}]_{4} / 0.1 \% \mathrm{Pt} / \mathrm{Cd}_{0.8} \mathrm{Zn}_{0.2} \mathrm{~S}$ versus the $0.1 \% \mathrm{Pt} / \mathrm{Cd}_{0.8} \mathrm{Zn}_{0.2} \mathrm{~S}$ (Table 2) which implies the importance of Pt content in the hybrid system. Apparently, the amount of Pt needs to be optimized for constructing an efficient Z-scheme. The effect of $\mathrm{Pt}$ on the Z-scheme is currently subjecting to a further study.

Accordingly, we proposed the charge transfer mechanisms for both cases separately, as shown in Figure 6. The overall solar-driven Z-scheme involves four steps, as described in Figure 6a. The steps are as follows: (1) charge generation in $\mathrm{ZnO}$ and $\mathrm{Cd}_{0.8} \mathrm{Zn}_{0.2} \mathrm{~S}$, (2) charge recombination on $\mathrm{Pt}$, (3) oxidation of the sacrificial reagent on the $\mathrm{VB}$ of $\mathrm{ZnO}$, and (4) hydrogen generation on the $\mathrm{CB}$ of $\mathrm{Cd}_{0.8} \mathrm{Zn}_{0.2} \mathrm{~S}$. This process happens only when both semiconductors are activated at the same time. On the other hand, simple charge transfer happens when only $\mathrm{Cd}_{0.8} \mathrm{Zn}_{0.2} \mathrm{~S}$ is excited, as shown in Figure $6 \mathrm{~b}$. The charge transfer process is also associated with four steps: (1) $\mathrm{Cd}_{0.8} \mathrm{Zn}_{0.2} \mathrm{~S}$ excitation, (2) electron transfer from $\mathrm{Cd}_{0.8} \mathrm{Zn}_{0.2} \mathrm{~S}$ to $\mathrm{ZnO}$ and then to $\mathrm{Pt}$, (3) photo-oxidation on $\mathrm{Cd}_{0.8} \mathrm{Zn}_{0.2} \mathrm{~S}$, and (4) photoreduction on Pt. In summary, the Z-scheme (Figure 6a) is formed under UV + vis light, whereas charge separation (Figure $6 \mathrm{~b}$ ) occurs under visible light on $\mathrm{ZnO} / 1 \% \mathrm{Pt} / \mathrm{Cd}(\mathrm{Zn}) \mathrm{S}$.

To further validate the proposed mechanism, femtosecond transient absorption (TA) measurements were performed on $\mathrm{ZnO}, \mathrm{ZnO} / \mathrm{Pt}, \mathrm{Cd}_{0.8} \mathrm{Zn}_{0.2} \mathrm{~S}, \quad \mathrm{Cd}_{0.8} \mathrm{Zn}_{0.2} \mathrm{~S} / \mathrm{Pt}$, and $\mathrm{ZnO} / \mathrm{Pt} /$ $\mathrm{Cd}_{0.8} \mathrm{Zn}_{0.2} \mathrm{~S}$ following $350 \mathrm{~nm}$ excitation, as shown in Figure 7A. The details of TA spectra are described in Figure 7A, where the spectral signatures were identified for both electrons and holes for $\mathrm{ZnO}$ and $\mathrm{Cd}_{0.8} \mathrm{Zn}_{0.2} \mathrm{~S}$. The spectral features of

Table 2. AQY\% of the CdZnS-Based System under Various Illumination Wavelengths

\begin{tabular}{|c|c|c|c|c|c|c|}
\hline catalysts & $\begin{array}{l}\text { wavelength } \\
(\mathrm{nm})\end{array}$ & $\mathrm{Cd}_{0.8} \mathrm{Zn}_{0.2} \mathrm{~S}$ & $0.1 \% \mathrm{Pt} / \mathrm{Cd}_{0.8} \mathrm{Zn}_{0.2} \mathrm{~S}$ & $1 \% \mathrm{Pt} / \mathrm{Cd}_{0.8} \mathrm{Zn}_{0.2} \mathrm{~S}$ & {$[\mathrm{ZnO}]_{4} / 0.1 \% \mathrm{Pt} / \mathrm{Cd}_{0.8} \mathrm{Zn}_{0.2} \mathrm{~S}$} & {$[\mathrm{ZnO}]_{4} / 1 \% \mathrm{Pt} / \mathrm{Cd}_{0.8} \mathrm{Zn}_{0.2} \mathrm{~S}$} \\
\hline \multirow{2}{*}{$\begin{array}{l}\text { apparent quantum yield } \\
\text { (AQY \%) }\end{array}$} & 365 & 3 & 20 & 14 & 11 & 34 \\
\hline & 460 & 9 & 16 & 10 & 10 & 16 \\
\hline
\end{tabular}




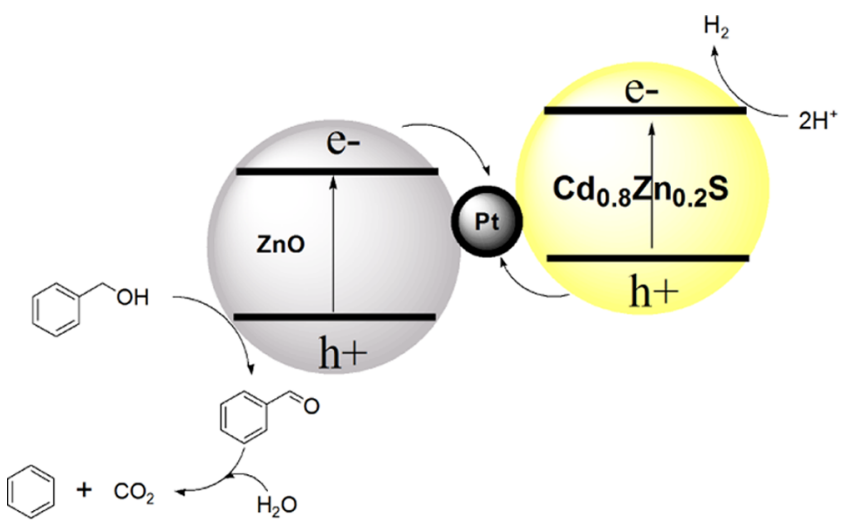

(a)

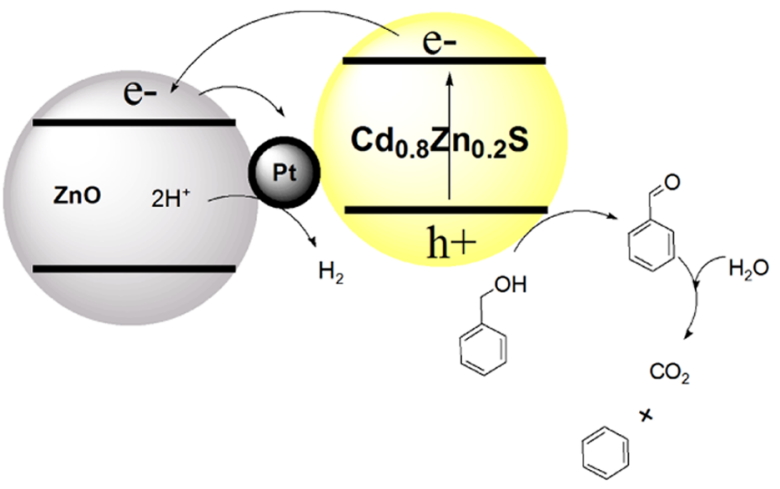

(b)

Figure 6. Charge transfer mechanism of the $\mathrm{ZnO} / \mathrm{Pt} / \mathrm{Cd}_{0.8} \mathrm{Zn}_{0.2} \mathrm{~S}$ system: (a) Z-scheme under $\mathrm{UV}$ light and (b) charge separation under visible light.
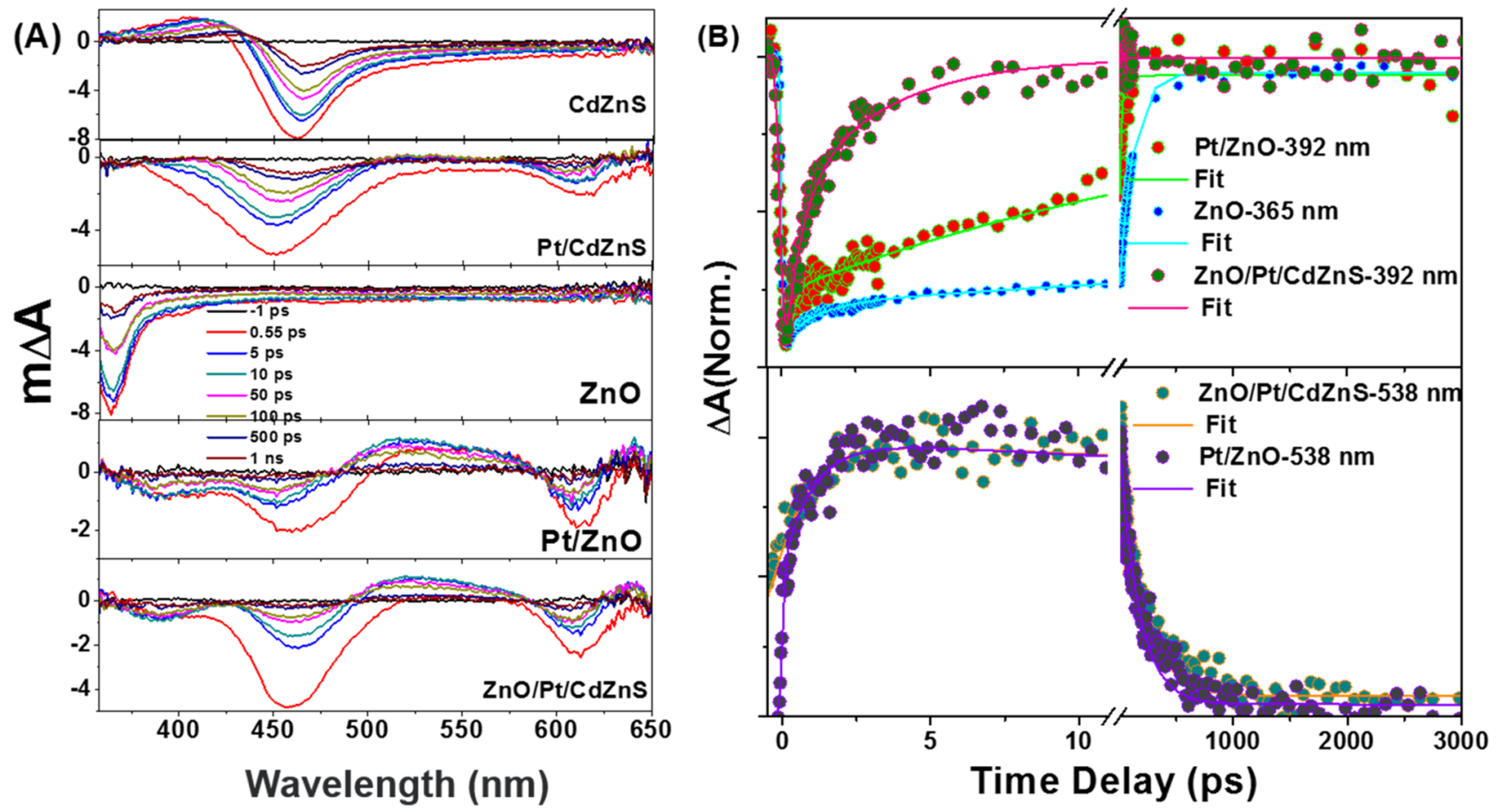

Figure 7. (A) Femtosecond (fs) transient absorption spectra of $\mathrm{CdZnS}, \mathrm{Pt} / \mathrm{CdZnS}, \mathrm{ZnO}, \mathrm{Pt} / \mathrm{ZnO}$, and $\mathrm{ZnO} / \mathrm{Pt} / \mathrm{CdZnS}$ in water at different time delays following $350 \mathrm{~nm}$ laser excitation and (B) normalized kinetics traces monitored at key wavelengths of $\mathrm{ZnO}, \mathrm{Pt} / \mathrm{ZnO}$, and $\mathrm{ZnO} / \mathrm{Pt} / \mathrm{CdZnS}$ and normalized kinetic decay traces of $\mathrm{ZnO}, \mathrm{Pt} / \mathrm{ZnO}$, and $\mathrm{ZnO} / \mathrm{Pt} / \mathrm{Cd}_{0.8} \mathrm{Zn}_{0.2} \mathrm{~S}$ in $0.5 \mathrm{mg} / \mathrm{mL}$ water suspension following $350 \mathrm{~nm}$ excitation with 90 $\mu \mathrm{J} / \mathrm{cm}^{2}$.

$\mathrm{Cd}_{0.8} \mathrm{Zn}_{0.2} \mathrm{~S}$ in terms of peak shapes and positions are similar to those observed in $\mathrm{CdS}^{24}$ and are assigned in the same manner. The TA feature around $420 \mathrm{~nm}$ decays rapidly, which can be attributed to hot excitons in $\mathrm{Cd}_{0.8} \mathrm{Zn}_{0.2} \mathrm{~S}^{25}$ This feature disappeared in $\mathrm{Cd}_{0.8} \mathrm{Zn}_{0.2} \mathrm{~S} / \mathrm{Pt}$ due to fast electron transfer from $\mathrm{Cd}_{0.8} \mathrm{Zn}_{0.2} \mathrm{~S}$ to $\mathrm{Pt}$. The transient bleach (TB) around 470 $\mathrm{nm}$ shows slow decay, indicating the domination of the longlived single exciton state, and it is attributed to the filling of the electron level, ${ }^{25}$ which is broadened when $\mathrm{Pt}$ is attached to $\mathrm{Cd}_{0.8} \mathrm{Zn}_{0.2} \mathrm{~S}$. Meanwhile, a fast TB feature at $610 \mathrm{~nm}$ appears, suggesting electron transfer from $\mathrm{CB}$ of $\mathrm{Cd}_{0.8} \mathrm{Zn}_{0.2} \mathrm{~S}$ to $\mathrm{Pt}^{26} \mathrm{~A}$ similar feature at a slightly different position $(615 \mathrm{~nm})$ was also observed in the case of $\mathrm{ZnO} / \mathrm{Pt}$, further indicating that $\mathrm{Pt}$ nanoparticles are the main exciton quenching pathway. ${ }^{25}$ In addition, the broad $\mathrm{TB}$ features at 392 and $460 \mathrm{~nm}$ are attributed to electron absorption from shallow trap (ST) states of $\mathrm{ZnO}$, whereas the broad photoinduced absorption (PA) peak at $538 \mathrm{~nm}$ can be assigned to hole absorption in $\mathrm{ZnO} / \mathrm{Pt}$. It is interesting to note that only one long-lived and highenergy exciton band was observed at $365 \mathrm{~nm}$ in pristine $\mathrm{ZnO}$, representing a band absorption of $3.2 \mathrm{eV}$, which resulted into electrons and holes in the presence of Pt.

Although TB signals at 470 and $610 \mathrm{~nm}$ of $\mathrm{Cd}_{0.8} \mathrm{Zn}_{0.2} \mathrm{~S}$ are stronger, they overlapped with those of $\mathrm{ZnO} / \mathrm{Pt}$ around the same region, making it difficult to analyze (Figure $7 \mathrm{~A}$ ). Therefore, the TB feature at $390 \mathrm{~nm}$ and PA at $538 \mathrm{~nm}$ of $\mathrm{ZnO}$ were chosen to monitor the effect of $\mathrm{Z}$-scheme (Figure 7B). All of the transient features of $\mathrm{ZnO} / \mathrm{Pt}, \mathrm{ZnO} / \mathrm{Pt} /$ $\mathrm{Cd}_{0.8} \mathrm{Zn}_{0.2} \mathrm{~S}$ at various wavelengths were fitted with biexponential and the relevant fitted parameters are summarized in Table 
Table 3. Fast and Slow Charge Carrier Lifetime of $\mathrm{ZnO} / \mathrm{Cd}_{0.8} \mathrm{Zn}_{0.2} \mathrm{~S}$ Based System at $350 \mathrm{~nm}$ Excitation with $90 \mu \mathrm{J} / \mathrm{cm}^{2}$

\begin{tabular}{lll}
\multicolumn{1}{c}{ system $(\lambda, \mathrm{nm})$} & \multicolumn{1}{c}{$\tau_{1}(\mathrm{ps})$} & \multicolumn{1}{c}{$\tau_{2}(\mathrm{ps})$} \\
$\mathrm{ZnO}(365 \mathrm{~nm})$ & $34.9 \pm 3.3(63 \%)$ & $634.2 \pm 90.6(37 \%)$ \\
$\mathrm{Pt} / \mathrm{ZnO}(392 \mathrm{~nm})$ & $0.2 \pm 0.05(40 \%)$ & $19.1 \pm 2(60 \%)$ \\
$\mathrm{ZnO} / \mathrm{Pt} / \mathrm{CdZnS}(392 \mathrm{~nm})$ & $0.118 \pm 0.05(73 \%)$ & $2.5 \pm 0.1(27 \%)$ \\
$\mathrm{Pt} / \mathrm{ZnO}(538 \mathrm{~nm})$ & $1 \pm 0.06(32 \%)$ & $202.6 \pm 28.3(-68 \%)$ \\
$\mathrm{ZnO} / \mathrm{Pt} / \mathrm{CdZnS}(538 \mathrm{~nm})$ & $1 \pm 0.07(33 \%)$ & $201 \pm 25.8(-67 \%)$
\end{tabular}

3. The electron feature of $\mathrm{ZnO} / \mathrm{Pt} / \mathrm{Cd}_{0.8} \mathrm{Zn}_{0.2} \mathrm{~S}$ at $392 \mathrm{~nm}$ shows faster decay compared to that of $\mathrm{ZnO} / \mathrm{Pt}$, whereas the hole feature at $538 \mathrm{~nm}$ displays a negligible change in both $\mathrm{ZnO} / \mathrm{Pt} / \mathrm{Cd}_{0.8} \mathrm{Zn}_{0.2} \mathrm{~S}$ and $\mathrm{ZnO} / \mathrm{Pt}$ (Figure $7 \mathrm{~B}$ ). This indicates faster depopulation of ST electron of $\mathrm{ZnO}$ through $\mathrm{Z}$-scheme. According to the proposed mechanism, as shown in Figure 6, the electron generated on $\mathrm{ZnO}$ was quenched with the hole generated on $\mathrm{Cd}_{0.8} \mathrm{Zn}_{0.2} \mathrm{~S}$ through $\mathrm{Pt}$, which resulted in faster electron decay compared to that of $\mathrm{ZnO} / \mathrm{Pt}$. On the other hand, the lifetime of the hole is not affected that much. Consequently, this process made it possible for the electron from $\mathrm{Cd}_{0.8} \mathrm{Zn}_{0.2} \mathrm{~S}$ and the hole from $\mathrm{ZnO}$ to participate in redox reactions. This kind of carrier dynamics features agrees well with the description of $\mathrm{Z}$-scheme, as shown in Figure 6.

The stability of the photocatalyst is considered to be the most important factor for practical applications. To investigate the stability of the $\mathrm{ZnO} / \mathrm{Pt} / \mathrm{Cd}_{0.8} \mathrm{Zn}_{0.2} \mathrm{~S}$ system, the time dependency of the photocatalytic $\mathrm{H}_{2}$ production over $[\mathrm{ZnO}]_{4} /$ $0.1 \% \mathrm{Pt} / \mathrm{Cd}_{0.8} \mathrm{Zn}_{0.2} \mathrm{~S}$ from an aqueous solution containing $2.5-$ $2.5 \% \mathrm{BnOH}-\mathrm{CH}_{3} \mathrm{CO}_{2} \mathrm{H}$ at $23 \%$ light intensity $(42.5 \mathrm{~mW} /$ $\mathrm{cm}^{2}$ ) of a xenon lamp was performed. The initial $\mathrm{pH}$ of the sacrificial reagent was around 2.5. The results (Figure 8) show that the $\mathrm{H}_{2}$ generation rate declines continuously and then stops completely after $2500 \mathrm{~min}$.

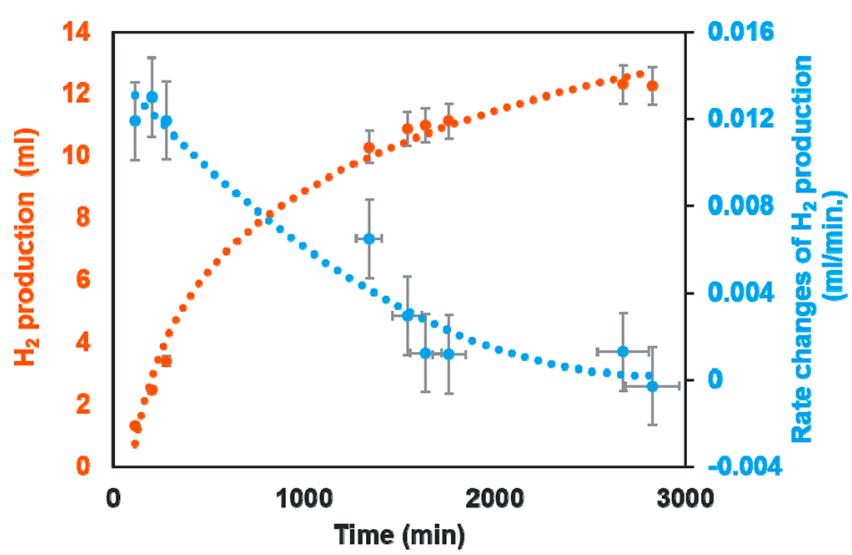

Figure 8. Stability test for photocatalytic $\mathrm{H}_{2}$ production with $[\mathrm{ZnO}]_{4} /$ $0.1 \% \mathrm{Pt} / \mathrm{Cd}_{0.8} \mathrm{Zn}_{0.2} \mathrm{~S}$. The reactor volume $(137 \mathrm{~mL})$, amounts of catalyst $(6 \mathrm{mg})$ and total flux $\left(42.5 \mathrm{~mW} / \mathrm{cm}^{2}\right)$.

Although the catalysts aggregated physically after a prolonged time, there was no color change of the catalyst. Furthermore, a similar $\mathrm{H}_{2}$ generation rate was obtained after washing the used catalyst with ethanol. This phenomenon suggests that benzyl aldehyde $(\mathrm{BzCHO})$ which was quantified by GC-MS, as one of the reaction intermediates, is strongly adsorbed on the surface of the catalyst, subsequently inhibiting the photocatalytic reaction. Moreover, the XPS analysis of catalysts before and after the reaction (Table 4) reveals a change of $\mathrm{Cd} / \mathrm{Zn}$ ratio from 1:2.7 to $1: 1.6$. This could be due to
$\mathrm{Zn}$ leaching during $\mathrm{H}_{2}$ generation, owing to the acidic nature of the sacrificial reagent.

Table 4. Bulk and Surface Compositions of the Fresh and Used Catalyst by ICP and XPS

\begin{tabular}{|c|c|c|c|c|}
\hline catalyst & \multicolumn{2}{|c|}{ bulk (ICP) } & \multicolumn{2}{|c|}{ surface (XPS) } \\
\hline compositions & $\mathrm{Cd} / \mathrm{Zn}(x)$ & $\mathrm{Pt}(\mathrm{wt} \%)$ & $\mathrm{Cd} / \mathrm{Zn}(x)$ & Pt (wt \%) \\
\hline fresh & $1: 4.7$ & 0.1 & $1: 2.7$ & \\
\hline used & $1: 1$ & 0.2 & 1:1.6 & \\
\hline
\end{tabular}

According to the experimental results and visual observation, one can conclude that the two main reasons for the deactivation of the photocatalyst are strong adsorption of $\mathrm{BzCHO}$ and dissolution of $\mathrm{ZnO}$.

\section{CONCLUSIONS}

In summary, a uniformly dispersed $\mathrm{ZnO} / \mathrm{Pt} / \mathrm{Cd}_{0.8} \mathrm{Zn}_{0.2} \mathrm{~S}$ photocatalyst exhibits high photocatalytic activity for hydrogen production when $2.5-2.5 \% \mathrm{v} / \mathrm{v} \mathrm{BnOH} / \mathrm{CH}_{3} \mathrm{CO}_{2} \mathrm{H}$ was used as the sacrificial reagent under xenon lamp irradiation (total light flux: $42.5 \mathrm{~mW} / \mathrm{cm}^{2}$ ). In particular, the highest photocatalytic rate $(10.2 \mathrm{mmol} / \mathrm{h} \mathrm{g})$ and AQY $(34 \%)$ were achieved with $[\mathrm{ZnO}]_{4} / 1 \% \mathrm{Pt} / \mathrm{Cd}_{0.8} \mathrm{Zn}_{0.2} \mathrm{~S}$, which are significantly higher than those of $1 \% \mathrm{Pt} / \mathrm{ZnO}$ and $1 \% \mathrm{Pt} / \mathrm{Cd}_{0.8} \mathrm{Zn}_{0.2} \mathrm{~S}$. These results are attributed to the effective $\mathrm{Z}$-scheme formation between $\mathrm{ZnO}$ and $\mathrm{Cd}_{0.8} \mathrm{Zn}_{0.2} \mathrm{~S}$ through Pt. A Z-scheme-based charge transfer mechanism was proposed by performing a time-resolved transient absorption study. Finally, a systematic study was conducted on the photocatalytic stability of the system. The results indicate that there are two main reasons for catalytic deactivation of $\mathrm{ZnO} / \mathrm{Pt} / \mathrm{Cd}_{0.8} \mathrm{Zn}_{0.2} \mathrm{~S}$, namely, (1) blockage of active sites caused by strong adsorption of $\mathrm{BzCHO}$ and (2) $\mathrm{ZnO}$ dissolution under acidic conditions, which will eventually destroy the Z-scheme. This work not only represents a systematic study on the $\mathrm{ZnO} / \mathrm{Pt} / \mathrm{Cd}_{0.8} \mathrm{Zn}_{0.2} \mathrm{~S}$ system but also provides new insights into the understanding of photocatalytic activities of metal oxide/metal/Cd(Zn)S hybrid systems.

\section{EXPERIMENTAL SECTION}

4.1. Synthesis of $\mathrm{ZnO} / \mathrm{Pt} / \mathrm{CdZnS}$. All reagents were of analytical grade, purchased from Sigma-Aldrich, and used without further purification. The detailed synthetic procedure used for preparing $\mathrm{Cd}_{0.8} \mathrm{Zn}_{0.2} \mathrm{~S}$-based hybrid materials is described below. ${ }^{12}$

4.1.1. Pt/ZnO. ${ }^{12} \mathrm{Zn}\left(\mathrm{CH}_{3} \mathrm{COO}\right)_{2} \cdot 2 \mathrm{H}_{2} \mathrm{O}(2.64 \mathrm{~g}, 12 \mathrm{mmol})$ was added to methanol $(210 \mathrm{~mL})$ in a $500 \mathrm{~mL}$ three-neck RBF, and the temperature was raised to $60{ }^{\circ} \mathrm{C}$. After $10 \mathrm{~min}, 30 \mathrm{~mL}$ of a methanolic solution of $\mathrm{KOH}(1.50 \mathrm{~g}, 26.7 \mathrm{mmol})$ was added dropwise to the reaction solution. The clear solution was stirred for another $2 \mathrm{~h}$ at $60{ }^{\circ} \mathrm{C}$ and then $50 \mathrm{~mL}$ of water was added. The resulting white precipitate was filtered, washed with water-methanol $(1: 1)$, and dried at $80^{\circ} \mathrm{C}$ for overnight to give $\mathrm{ZnO}$ in quantitative yield. $\mathrm{H}_{4} \mathrm{PtCl}_{6}(1 \mathrm{mg} \mathrm{Pt} / \mathrm{mL}, 12 \mathrm{~mL})$ was 
added dropwise to a methanol solution of $\mathrm{ZnO}(1 \mathrm{~g}, 12.3$ mmol) nanocrystals, followed by $1.5 \mathrm{~mL}$ of $\mathrm{NaBH}_{4}(40 \mathrm{mM})$ aqueous solution. The solution was stirred for $10 \mathrm{~min}$. The resulting suspension was centrifuged, washed with methanol, and dried in air to give $\mathrm{Pt} @ \mathrm{ZnO}$ in quantitative yield.

4.1.2. $\mathrm{ZnO} / \mathrm{Pt} / \mathrm{Cd} d_{0.8} \mathrm{Zn}_{0.2} \mathrm{~S}^{12} \mathrm{ZnO} / \mathrm{Pt}(0.32 \mathrm{~g}, 4 \mathrm{mmol})$ nanoparticles were dispersed in $70 \mathrm{~mL}$ of methanol, and the temperature was raised to $60{ }^{\circ} \mathrm{C}$. To form $\mathrm{Cd}_{0.8} \mathrm{Zn}_{0.2} \mathrm{~S}$ layers on the particles, the required amount of zinc acetate $(0.2 \mathrm{mmol})$ from zinc acetate stock solution $(80 \mathrm{mM}, 2.5 \mathrm{~mL})$ and cadmium acetate $(0.8 \mathrm{mmol})$ from its stock solution $(80 \mathrm{mM}$, $10 \mathrm{~mL}$ ) were added to the suspension, the suspension was stirred for $15 \mathrm{~min}$ at $60^{\circ} \mathrm{C}$, and then sodium sulfide $(2 \mathrm{mmol})$ from the $(100 \mathrm{mM}, 20 \mathrm{~mL})$ methanolic stock solution was added dropwise. The resulting suspension was stirred for $1 \mathrm{~h}$. The precipitates were separated by centrifugation, washed with $\mathrm{H}_{2} \mathrm{O} / \mathrm{MeOH}$ (1:1) mixture, and dried at $80{ }^{\circ} \mathrm{C}$ overnight to give the final product of $[\mathrm{ZnO}]_{4} / 1 \% \mathrm{Pt} / \mathrm{Cd}_{0.8} \mathrm{Zn}_{0.2} \mathrm{~S}(0.4 \mathrm{~g}, 88 \%$ in yield).

4.1.3. $P t / C d_{0.8} Z n_{0.2} S$. Zinc acetate $(0.2 \mathrm{mmol})$ from zinc acetate stock solution $(80 \mathrm{mM}, 2.5 \mathrm{~mL})$ and cadmium acetate $(0.8 \mathrm{mmol})$ from its $(80 \mathrm{mM}, 10 \mathrm{~mL})$ stock solution were mixed, the mixture was stirred for $15 \mathrm{~min}$ at $60{ }^{\circ} \mathrm{C}$, and then sodium sulfide $(2 \mathrm{mmol})$ from $(100 \mathrm{mM}, 20 \mathrm{~mL})$ methanolic stock solution was added dropwise. The resulting suspension was stirred for $1 \mathrm{~h}$. The precipitates were separated by centrifugation, washed with the $\mathrm{H}_{2} \mathrm{O} / \mathrm{MeOH}$ (1:1) mixture, and dried at $60{ }^{\circ} \mathrm{C}$ overnight to give the final product of $\mathrm{Cd}_{0.8} \mathrm{Zn}_{0.2} \mathrm{~S}$ in quantitative yield. Photodeposition of $\mathrm{Pt}$ on $\mathrm{Cd}_{0.8} \mathrm{Zn}_{0.2} \mathrm{~S}$ was carried out by mixing of $\mathrm{Cd}_{0.8} \mathrm{Zn}_{0.2} \mathrm{~S}(100 \mathrm{mg})$ with $1 \mathrm{~mL}$ of stock solution of $\mathrm{H}_{4} \mathrm{PtCl}_{6}(1 \mathrm{mg} / \mathrm{mL}(\mathrm{Pt}))$ in $\mathrm{BnOH} / \mathrm{AcOH}(2.5-2.5 \% \mathrm{v} / \mathrm{v})$. The resulting mixture was illuminated under UV $(\lambda=360 \mathrm{~nm})$ light with the intensity of 5 $\mathrm{mW} / \mathrm{cm}^{2}$ for $4 \mathrm{~h}$. The resulting solution was filtered, washed with water, and dried at $80{ }^{\circ} \mathrm{C}$ overnight to obtain the desired product $1 \% \mathrm{Pt} / \mathrm{Cd}_{0.8} \mathrm{Zn}_{0.2} \mathrm{~S}$ in quantitative yield.

4.2. Characterization. UV-vis absorption spectra of the powdered catalysts were collected over the wavelength range of 250-700 nm on a Thermo Fisher Scientific spectrophotometer equipped with praying mantis diffuse reflectance accessory. Absorbance $(A)$ and reflectance $(\% R)$ of the samples were measured. The reflectance $(\% R)$ data were used to calculate the band gap of the samples using the Tauc plot (KubelkaMunk function).

XRD spectra were recorded using a Bruker D8 Advance Xray diffractometer. $\mathrm{Cu} \mathrm{K} \alpha(\lambda=1.5406 \AA)$ radiation over the range of $2 \theta$; interval between 20 and $90^{\circ}$ with a step size of $0.010^{\circ}$ and a step time of $0.2 \mathrm{~s} / \mathrm{step}$ was used.

The XP spectra of the samples were collected by a Thermo Scientific Escalab $250 \mathrm{XI}$ XP spectrometer with an $\mathrm{Al} \mathrm{K} \alpha$ X-ray source. The X-ray spot size was $650 \times 650 \mu \mathrm{m}^{2}$. Charge compensation was carried out using a standard flood gun. Before collecting XPS data, samples were etched using Ar ions for $5 \mathrm{~min}$ at an ion energy of $1000 \mathrm{eV}$. Data were acquired using the settings given in Table 5 .

Table 5. XPS Setting for Date Acquisition

\begin{tabular}{lcccc}
\multicolumn{1}{c}{ scan } & PE $(\mathrm{eV})$ & dwell time $(\mathrm{ms})$ & step size $(\mathrm{eV})$ & \# of scans \\
survey & 100 & 100 & 1 & 1 \\
high resolution & 30 & 100 & 0.1 & $10-30$
\end{tabular}

All peaks were corrected with respect to the binding energy of the adventitious C 1 s peak at $284.5 \mathrm{eV}$. All peaks were fitted using the SMART background option and Lorentzian/ Gaussian.

The concentrations of $\mathrm{Zn}, \mathrm{Cd}, \mathrm{S}$, and Pt were measured by inductively coupled plasma optical emission spectroscopy on a Varian 720-ES instrument. TEM samples were dispersed in alcohol, and a drop of the suspension was placed over a grid with holey-carbon film. The TEM images were collected using a FEI Tecnai F20 microscope operating at $200 \mathrm{kV}$.

4.3. Photocatalytic Test. Photocatalytic reactions were performed in a $137 \mathrm{~mL}$ volume Pyrex glass reactor using 6-30 $\mathrm{mg}$ of catalyst. Various volume ratios $(30 \mathrm{~mL})$ of benzyl alcohol/acidic acid $(\mathrm{BnOH} / \mathrm{AcOH})$ aqueous solutions were used. The slurry was purged with $\mathrm{N}_{2}$ gas to remove any $\mathrm{O}_{2}$ and subjected to constant stirring before the reaction. The reactor was then exposed to UV light $(100 \mathrm{~W}$ ultraviolet lamp H144GC-100 Sylvania par 38 with a flux of around $5 \mathrm{~mW} / \mathrm{cm}^{2}$ at a distance of $5 \mathrm{~cm}$ ). Similarly, to evaluate the UV + visible light activity, a xenon lamp (Asahi spectra MAX-303) with a total flux of $42.5 \mathrm{~mW} / \mathrm{cm}^{2}$ ( $\mathrm{UV} \sim 3.0 \mathrm{~mW} / \mathrm{cm}^{2}$ and visible (up to $650 \mathrm{~nm})$ ) at a distance of $2 \mathrm{~cm}$ was used. Product analyses were performed by a gas chromatograph equipped with a thermal conductivity detector connected to a Porapak Q packed column $(2 \mathrm{~m})$ at $45^{\circ} \mathrm{C}$, and $\mathrm{N}_{2}$ was used as a carrier gas. The $\mathrm{BzCHO}$ content was monitored by GC-MS from Thermo Scientific (Waltham, MA USA) equipped with trance 1300 (GC) and ISQ single quadrupole (MS). Apparent quantum yields (AQYs) at various wavelengths defined by eq $1^{27}$ were calculated by data obtained using monochromatic light-emitting diode (365$750 \mathrm{~nm}$ ) at a distance of $2 \mathrm{~cm}$. The corresponding light intensities were measured with a GL Spectis 5.0 Touch spectrometer.

$$
\begin{aligned}
\text { AQY\% } & =\frac{\text { number of excited electron }}{\text { the number of incident photon }} \\
& =\frac{2 \times \text { the number of evolved hydrogen molecules }}{\text { the number of incident photon }}
\end{aligned}
$$

4.4. Femtosecond Transient Absorption (TA) Measurements. Time-resolved absorption decays of the catalyst suspension in water were measured with a pump-probe setup, in which a white light continuum probe pulse was generated in a $2 \mathrm{~mm}$ thick sapphire plate contained in an Ultrafast System LLC spectrometer using few microjoules energy of an $800 \mathrm{~nm}$ pulse. The fundamental output delivered by a $\mathrm{Ti} /$ sapphire femtosecond regenerative amplifier operating at $800 \mathrm{~nm}$ with $35 \mathrm{fs}$ pulses and a repetition rate of $1 \mathrm{kHz}$. Spectrally tunable $(240-2600 \mathrm{~nm})$ femtosecond pulses generated by an optical parametric amplifier (Light Conversion Ltd) and a white light continuum were used, respectively, as the pump (excitation) and probe beams in a pump-probe experimental setup (Helios). The details of the experimental setup can be found elsewhere. $^{28}$

\section{ASSOCIATED CONTENT}

\section{Supporting Information}

The Supporting Information is available free of charge on the ACS Publications website at DOI: 10.1021/acsomega.7b00767.

$\mathrm{XP}$ survey spectra of $\mathrm{ZnO} / \mathrm{CdZnS}$-based systems (PDF) 


\section{AUTHOR INFORMATION}

\section{Corresponding Authors}

*E-mail: tisimjan@sabic.com (T.T.I.).

*E-mail: Idrissh@sabic.com (H.I.).

\section{ORCID}

Tayirjan Taylor Isimjan: 0000-0003-1735-481X

Partha Maity: 0000-0002-0293-7118

Jordi Llorca: 0000-0002-7447-9582

Manas R. Parida: 0000-0003-2091-4507

Omar F. Mohammed: 0000-0001-8500-1130

Hicham Idriss: 0000-0001-8614-7019

\section{Notes}

The authors declare no competing financial interest.

\section{ACKNOWLEDGMENTS}

This work was financially supported by SABIC-CRD at KAUST. J.L. is Serra Húnter Fellow and is grateful to the ICREA Academia program and MINECO/FEDER grant ENE2015-63969-R.

\section{REFERENCES}

(1) Bard, A. J.; Fox, M. A. Artificial Photosynthesis: Solar Splitting of Water to Hydrogen and Oxygen. Acc. Chem. Res. 1995, 28, 141-145. (2) (a) Elward, J. M.; Chakraborty, A. Effect of dot size on exciton binding energy and electron-hole recombination probability in CdSe quantum dots. J. Chem. Theory Comput. 2013, 9, 4351-4359. (b) Le Formal, F.; Pendlebury, S. R.; Cornuz, M.; Tilley, S. D.; Grätzel, M.; Durrant, J. R. Back electron-hole recombination in hematite photoanodes for water splitting. J. Am. Chem. Soc. 2014, 136, 25642574.

(3) Li, Q.; Meng, H.; Zhou, P.; Zheng, Y.; Wang, J.; Yu, J.; Gong, J. $\mathrm{Zn} 1-\mathrm{xCdxS}$ solid solutions with controlled bandgap and enhanced visible-light photocatalytic H2-production activity. ACS Catal. 2013, 3, 882-889.

(4) (a) Zhang, J.; Yu, J.; Jaroniec, M.; Gong, J. R. Noble Metal-Free Reduced Graphene Oxide-ZnxCd1-xS Nanocomposite with Enhanced Solar Photocatalytic H2-Production Performance. Nano Lett. 2012, 12, 4584-4589. (b) Yu, Y.; Zhang, J.; Wu, X.; Zhao, W.; Zhang, B. Nanoporous single-crystal-like CdxZn1-xS nanosheets fabricated by the cation-exchange reaction of inorganic-organic hybrid $\mathrm{ZnS}$ Amine with cadmium ions. Angew. Chem., Int. Ed. 2012, 51, 897-900.

(5) Liu, M.; Wang, L.; Lu, G.; Yao, X.; Guo, L. Twins in Cd1-xZnxS solid solution: Highly efficient photocatalyst for hydrogen generation from water. Energy Environ. Sci. 2011, 4, 1372-1378.

(6) Xiong, Z.; Zheng, M.; Zhu, C.; Zhang, B.; Ma, L.; Shen, W. Onestep synthesis of highly efficient three-dimensional Cd1-xZnxS photocatalysts for visible light photocatalytic water splitting. Nanoscale Res. Lett. 2013, 8, 334.

(7) Zhou, H.; Liu, Q.; Liu, W.; Ge, J.; Lan, M.; Wang, C.; Geng, J.; Wang, P. Template-free preparation of volvox-like CdxZn1-xS nanospheres with cubic phase for efficient photocatalytic hydrogen production. Chem. - Asian J. 2014, 9, 811-818.

(8) (a) Ida, S.; Takashiba, A.; Koga, S.; Hagiwara, H.; Ishihara, T. Potential gradient and photocatalytic activity of an ultrathin $p-n$ junction surface prepared with two-dimensional semiconducting nanocrystals. J. Am. Chem. Soc. 2014, 136, 1872-1878. (b) Zheng, H.; Li, Y.; Liu, H.; Yin, X.; Li, Y. Construction of heterostructure materials toward functionality. Chem. Soc. Rev. 2011, 40, 4506-4524.

(9) (a) Kothe, T.; Plumeré, N.; Badura, A.; Nowaczyk, M. M.; Guschin, D. A.; Rögner, M.; Schuhmann, W. Combination of a photosystem 1-based photocathode and a photosystem 2-based photoanode to a z-scheme mimic for biophotovoltaic applications. Angew. Chem., Int. Ed. 2013, 52, 14233-14236. (b) Zhou, P.; Yu, J.; Jaroniec, M. All-solid-state Z-scheme photocatalytic systems. Adv. Mater. 2014, 26, 4920-4935.
(10) (a) Srinivasan, N.; Sakai, E.; Miyauchi, M. Balanced Excitation between Two Semiconductors in Bulk Heterojunction Z-Scheme System for Overall Water Splitting. ACS Catal. 2016, 6, 2197-2200. (b) Wang, Q.; Hisatomi, T.; Jia, Q.; Tokudome, H.; Zhong, M.; Wang, C.; Pan, Z.; Takata, T.; Nakabayashi, M.; Shibata, N.; Li, Y.; Sharp, I. D.; Kudo, A.; Yamada, T.; Domen, K. Scalable water splitting on particulate photocatalyst sheets with a solar-to-hydrogen energy conversion efficiency exceeding 1\%. Nat. Mater. 2016, 15, 611-615. (c) Wang, Q.; Li, Y.; Hisatomi, T.; Nakabayashi, M.; Shibata, N.; Kubota, J.; Domen, K. Z-scheme water splitting using particulate semiconductors immobilized onto metal layers for efficient electron relay. J. Catal. 2015, 328, 308-315. (d) Li, H.; Tu, W.; Zhou, Y.; Zou, Z. Z-Scheme Photocatalytic Systems for Promoting Photocatalytic Performance: Recent Progress and Future Challenges. Adv. Sci. 2016, 3, No. 1500389.

(11) Mukhopadhyay, S.; Mondal, I.; Pal, U.; Devi, P. S. Fabrication of hierarchical $\mathrm{ZnO} / \mathrm{CdS}$ heterostructured nanocomposites for enhanced hydrogen evolution from solar water splitting. Phys. Chem. Chem. Phys. 2015, 17, 20407-20415.

(12) Lingampalli, S. R.; Gautam, U. K.; Rao, C. N. R. Highly efficient photocatalytic hydrogen generation by solution-processed $\mathrm{ZnO} / \mathrm{Pt} /$ $\mathrm{CdS}, \mathrm{ZnO} / \mathrm{Pt} / \mathrm{Cd} 1-\mathrm{xZnxS}$ and $\mathrm{ZnO} / \mathrm{Pt} / \mathrm{CdS} 1$-xSex hybrid nanostructures. Energy Environ. Sci. 2013, 6, 3589-3594.

(13) Han, Z.; Chen, G.; Li, C.; Yu, Y.; Zhou, Y. Preparation of 1D cubic $\mathrm{Cd}_{08} \mathrm{Zn}_{02} \mathrm{~S}$ solid-solution nanowires using levelling effect of TGA and improved photocatalytic $\mathrm{H}_{2}$-production activity. J. Mater. Chem. A 2015, 3, 1696-1702.

(14) Hsu, Y.-Y.; Suen, N. T.; Chang, C. C.; Hung, S. F.; Chen, C. L.; Chan, T. S.; Dong, C. L.; Chan, C. C.; Chen, S. Y.; Chen, H. M. Heterojunction of Zinc Blende/Wurtzite in Zn1-xCdxS Solid Solution for Efficient Solar Hydrogen Generation: X-ray Absorption/Diffraction Approaches. ACS Appl. Mater. Interfaces 2015, 7, 22558-22569.

(15) Gorczyca, I.; Suski, T.; Christensen, N. E.; Svane, A. Size effects in band gap bowing in nitride semiconducting alloys. Phys. Rev. B 2011, 83, No. 153301.

(16) Tauc, J. Optical properties and electronic structure of amorphous Ge and Si. Mater. Res. Bull. 1968, 3, 37-46.

(17) Moulder, J. F.; Stickle, W. F.; Sobol, P. E.; Bomben, K. D. Handbook of X-ray Photoelectron Spectroscopy; Perkin-Elmer: Eden Prairie, MN, 1992; pp 1-261.

(18) Durán, J. D. G.; Guindo, M. C.; Delgado, A. V.; GonzálezCaballero, F. Surface chemical analysis and electrokinetic properties of synthetic spherical mixed zinc-cadmium sulfides. J. Colloid Interface Sci. 1997, 193, 223-233.

(19) (a) Erdem, B.; Hunsicker, R. A.; Simmons, G. W.; Sudol, E. D.; Dimonie, V. L.; El-Aasser, M. S. XPS and FTIR Surface Characterization of $\mathrm{TiO}_{2}$ Particles Used in Polymer Encapsulation. Langmuir 2001, 17, 2664-2669. (b) Haija, M. A.; Guimond, S.; Uhl, A.; Kuhlenbeck, H.; Freund, H. J. Adsorption of water on thin $\mathrm{V}_{2} \mathrm{O}_{3}(0001)$ films. Surf. Sci. 2006, 600, 1040-1047.

(20) Abe, T.; Kashiwaba, Y.; Baba, M.; Imai, J.; Sasaki, H. XPS analysis of p-type Cu-doped CdS thin films. Appl. Surf. Sci. 2001, 175176, 549-554.

(21) Mason, M. G. Electronic structure of supported small metal clusters. Phys. Rev. B 1983, 27, 748-762.

(22) Kozlova, E. A.; Cherepanova, S. V.; Markovskaya, D. V.; Saraev, A. A.; Gerasimov, E. Y.; Parmon, V. N. Novel photocatalysts Pt/ $\mathrm{Cd}_{1-\mathrm{x}} \mathrm{Zn}_{\mathrm{x}} \mathrm{S} / \mathrm{ZnO} / \mathrm{Zn}(\mathrm{OH})_{2}$ : Activation during hydrogen evolution from aqueous solutions of ethanol under visible light. Appl. Catal., B 2016, 183, 197-205.

(23) Yan, J.; Wu, H.; Chen, H.; Zhang, Y.; Zhang, F.; Liu, S. F. Fabrication of $\mathrm{TiO} 2 / \mathrm{C} 3 \mathrm{~N} 4$ heterostructure for enhanced photocatalytic Z-scheme overall water splitting. Appl. Catal., B 2016, 191, $130-137$.

(24) (a) Ben-Shahar, Y.; Scotognella, F.; Waiskopf, N.; Kriegel, I.; Dal Conte, S.; Cerullo, G.; Banin, U. Effect of surface coating on the photocatalytic function of hybrid CdS-Au nanorods. Small 2014, 11, 462-471. (b) Ben-Shahar, Y.; Scotognella, F.; Waiskopf, N.; Kriegel, 
I.; Dal Conte, S.; Cerullo, G.; Banin, U. Effect of surface coating on the photocatalytic function of hybrid CdS-Au nanorods. Small 2015, 11, 462-471. (c) Cooper, J. K.; Cao, J.; Zhang, J. Z. Exciton dynamics of $\mathrm{CdS}$ thin films produced by chemical bath deposition and DC pulse sputtering. ACS Appl. Mater. Interfaces 2013, 5, 7544-7551. (d) Wilker, M. B.; Shinopoulos, K. E.; Brown, K. A.; Mulder, D. W.; King, P. W.; Dukovic, G. Electron transfer kinetics in $\mathrm{CdS}$ nanorod-[FeFe]hydrogenase complexes and implications for photochemical $\mathrm{H} 2$ generation. J. Am. Chem. Soc. 2014, 136, 4316-4324. (e) Zhu, H.; Chen, Z.; Wu, K.; Lian, T. Wavelength dependent efficient photoreduction of redox mediators using type II $\mathrm{ZnSe} / \mathrm{CdS}$ nanorod heterostructures. Chem. Sci. 2014, 5, 3905-3914.

(25) Wu, K.; Zhu, H.; Liu, Z.; Rodríguez-Córdoba, W.; Lian, T. Ultrafast charge separation and long-lived charge separated state in photocatalytic CdS-Pt nanorod heterostructures. J. Am. Chem. Soc. 2012, 134, 10337-10340.

(26) Wu, K.; Zhu, H.; Lian, T. Ultrafast Exciton Dynamics and LightDriven H2 Evolution in Colloidal Semiconductor Nanorods and PtTipped Nanorods. Acc. Chem. Res. 2015, 48, 851-859.

(27) Liu, M.; Wang, L.; Lu, G.; Yao, X.; Guo, L. Twins in Cd1-xZnxS solid solution: Highly efficient photocatalyst for hydrogen generation from water. Energy Environ. Sci. 2011, 4, 1372-1378.

(28) (a) Sun, J.; Yu, W.; Usman, A.; Isimjan, T. T.; Dgobbo, S.; Alarousu, E.; Takanabe, K.; Mohammed, O. F. Generation of Multiple Excitons in Ag2S Quantum Dots: Single High-Energy versus MultiplePhoton Excitation. J. Phys. Chem. Lett. 2014, 5, 659-665. (b) ElBallouli, A. O.; Alarousu, E.; Usman, A.; Pan, J.; Bakr, O. M.; Mohammed, O. F. Real-Time Observation of Ultrafast Intraband Relaxation and Exciton Multiplication in PbS Quantum Dots. ACS Photonics 2014, 1, 285-292. 